\title{
ERJ
}

Engineering Research Journal

Faculty of Engineering

Minoufiya University

\section{OPERATION OF CENTRIFUGAL PUMP AT PART LOAD CONDITIONS}

\author{
M. A. Hosien and S. M. Selim
}

\author{
Mechanical Power Engineering Department, Faculty of Engineering, \\ Minoufiya University, Shebin El-kom, Egypt
}

\begin{abstract}
The paper presents the results of experimental studies on the onset, extent and structure of the flow recirculations at both inlet and outlet of a radial pump impeller. The study was conducted a various flow rates and a rotational speed of $2500 \mathrm{rpm}$. Balances of mass, momentum and energy were determined, and the losses prevalent at part load conditions under consideration of flow recirculation's were analyzed with the aid of the measured distributions of velocity and total pressure near impeller inlet and outlet. The results showed that the recirculating flow in the inlet and the outlet appeared for flow rate ratios $\mathrm{Q} / \mathrm{Q}_{\mathrm{opt}} \leq 0.7$ and $\mathrm{Q} / \mathrm{Q}_{\mathrm{opt}} \leq 1$, respectively. At zero flow rate the ratio of the suction recirculating flow $\left(\mathrm{Q}_{\mathrm{r}, \mathrm{s}}\right)$ to the optimum flow rate $\left(\mathrm{Q}_{\mathrm{opt}}\right)$ is 0.6 approximately. Also at zero flow the discharge recirculating flow $\left(\mathrm{Q}_{\mathrm{r}, \mathrm{d}}\right)$ was almost twice as larger as $\left(\mathrm{Q}_{\mathrm{r}, \mathrm{s}}\right)$. For the test impeller the critical flow rate at which the recirculating flow occurred at outlet was larger than that at inlet. In addition, the results indicated that the transfer of moment of momentum and energy to the recirculating flow which takes place inside the impeller increased with decreasing the flow rate. Analysis of losses indicated that the energy transferred to the recirculating flows could be regarded as additional impeller losses.

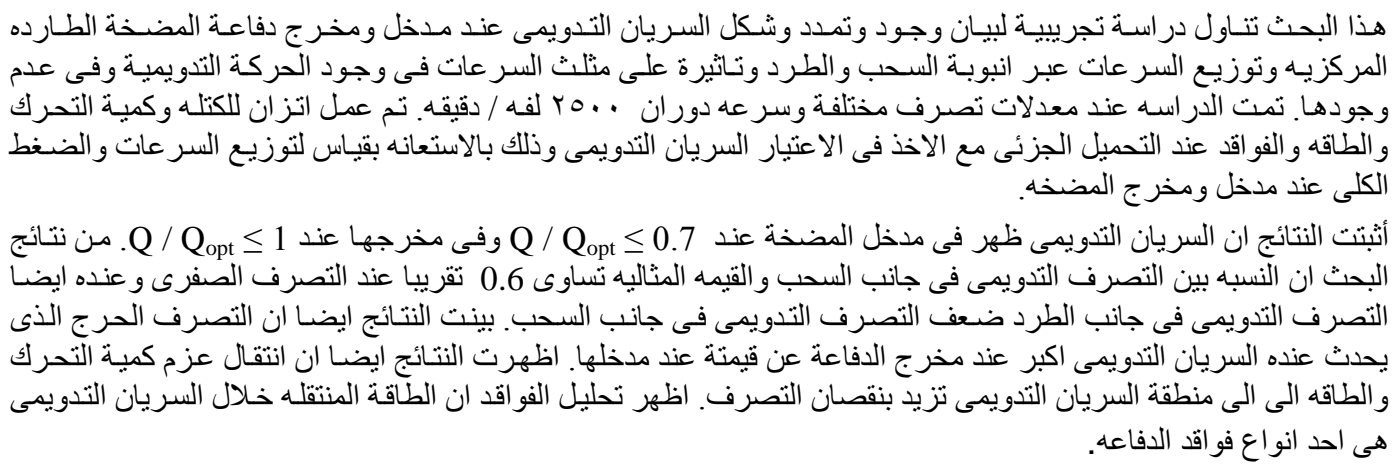

Keywords: Radial impeller pumps- part load conditions-flow recirculation.

\section{INTRODUCTION}

Numerous studies have been done in the performance of centrifugal pumps near their best efficiency point. At present the performance of pumps near the best efficiency point can be predicted by available data with sufficient accuracy. For minimum energy consumption and trouble - free operation, pumps should ideally be operated between $80 \%$ and $100 \%$ best efficiency point. As this is not always possible or practical, pumps will often operate at lower flows. It is therefore important that the minimum flow for continuous trouble free operation be carefully considered by the pump designer. Many applications require operation over a wide range of capacities, including extremely low flows and shutoff, for extended periods of time. Such pumps are vulnerable to surging, recirculation, cavitation, noise and vibration. These noise and vibration may be caused by development of the internal recirculation at the inlet and outlet of an impeller at flows below the capacity of best efficiency point. In addition flow recirculation gives rise to intensive interactions between the impeller and neighboring stationary parts of the pump which affect Q - H curve, power input, efficiency and required net positive suction head. The subject of internal recirculation, until very recently, had been understood by only a small number of pump designers. Frasers [1 and 2] gave exact formulas to calculate the flow at which internal recirculation would start at the suction once certain geometric data were known about an impeller and provided close approximation curves in the event that these data are not readily available. Reduced flow rate can result in pressure fluctuations, cavitation and overheating [3, 4]. These effects are not covered by the classical 
theory of centrifugal pumps, which leads to good results in the operating near best efficiency point (B.E.P). The different effects of flow recirculation are often defined by the term "recirculation losses", although it is not exactly clear what the actual nature of these "losses" is. Knowledge of this nature is, however, necessary for understanding the behavior of flow recirculation and their effects.

Investigators [5-10] results at very low flow rates showed that the shape of the flow field along the suction pipe is very complex, and the region near the pipe wall is characterized by the flow leaving the impeller. In between the wall regions there is a region where the flow is entering the impeller with the core in the middle. The important concluded point was that the creation of first bubbles was noticed at relative flow $\mathrm{Q} / \mathrm{Q}_{\mathrm{opt}}=0.7$. Salemi and Di Matteo [11] had conducted experiments to measure the velocity components in the suction pipe at $45 \mathrm{~mm}$ from the impeller eye of a centrifugal pump. The tests were conducted using two impellers, one with eight blades and the other with six blades. Their results indicated that the flow approaching the impeller presents a uniform pattern from highest flow rate up to a critical one, which is $0.57 \mathrm{Q}_{\mathrm{opt}}$ for eight blades impeller and $0.64 \mathrm{Q}_{\text {opt }}$ for six blades impeller. At this critical flow rate, suddenly a reverse flow with a positive swirling component developed. The reverse flow increases while the flow rate decreases, and the region of the reverse flow spreads in the central part of the test plane. Dupont [12] stated that for radial diffuser pump the minimum pressure coefficient occurs on the suction side close to the shroud at relative flow rate of $55 \%$. He attributed that to the re-circulation that takes place at part load close to the impeller shroud, locally reducing the inlet flow angle. Hofmann, et al [13] studied experimentally the similarities and geometrical effects on rotating cavitation in two scaled centrifugal pumps. They used a stroboscopic light source to observe the state of rotating cavitation. Their experiments indicated that rotating cavitation was observed at relative flow rates below $70 \%$. This phenomenon is assigned to the onset of re-circulatory flow on the leading edge of the blades. Up to now a little is know about the characteristics when centrifugal pumps operate under extremely low capacities. In addition, the theory of an ideal fluid applied to a centrifugal impeller is simplified form gives certain information about flow field in a pump operates near the best efficiency point. At small flow rate and having real fluid, the flow conditions are quite different, because the flow patterns break off the blades. Wuibaut et al. [14] summarized a complementary flow analysis in design and off-design operating conditions for vaned diffuser based on a dedicated post processing technique. Off design conditions are often related to recirculation problems at partial flow rates.
Recirculation or reverse flow can be defined by the fact that the fluid goes through a flow cross section with velocities havins opposite arithmetic signs [15]. Bois [16] presented schematically, for a meridional section in a radial flow pump, the difference between a well- developed flow near design conditions and a partial flow with recirculation in the inlet and the outlet part of the impeller. Bois [16] stated that reverse flow can occur either on the hub side or the shroud one, or both sides simultaneously. Statistical studies clearly show that the ratio of impeller recirculated mass flow over optimal mass flow increases with specific speed [17]. Feng et al. [18] provided flow visualization on complex internal flows in a radial diffuser pump under part-load conditions by using the three-dimensional NavierStokes code CFX-10 with Detached Eddy Simulation (DES) turbulence model. Particle Image Velocimetry (PIV) measurements have been conducted to validate numerical results. The CFD results showed good agreements with experimental ones on both the phase-averaged velocity fields and turbulence field.

Due to the large discrepancies among conditions required by theory and the real conditions in a pump, it is necessary to rely on the experimental data. Therefore, the aim of the present study is to determine the influence of flow recirculation on the energy transfer inside an impeller of a centrifugal pump. In addition, power balances and loss analysis under particular consideration of flow recirculation's are presented.

\section{TEST EQUPMENT AND TEST METHOD}

\subsection{Test Apparatus}

The general arrangement of the test apparatus is indicated in a schematic diagram as shown in Fig. 1. The flow system is a closed circuit consisting of two main lines, suction and the delivery linens. The suction pipe is fitted to the main tank through a hole at $(10 \mathrm{~cm})$ height from the bottom of the tank, while the delivery pipe is connected through a hole at height of $(100 \mathrm{~cm})$ from the bottom of the tank. Immediately in the front of the impeller the suction pipe is straight with $0.5 \mathrm{~m}$ long to the control suction valve. Two flatted Pitot tube were inserted at entrance of the pump at a distance of $(15 \mathrm{~mm})$ from the inlet and at the outlet of the pump at $(8 \mathrm{~mm})$ downstream of the impeller outlet for measuring the flow velocity distribution through the cross-section of the suction pipe and pump outlet. Figure (2) shows sketch of the flow field recirculation's at impeller inlet and outlet. 


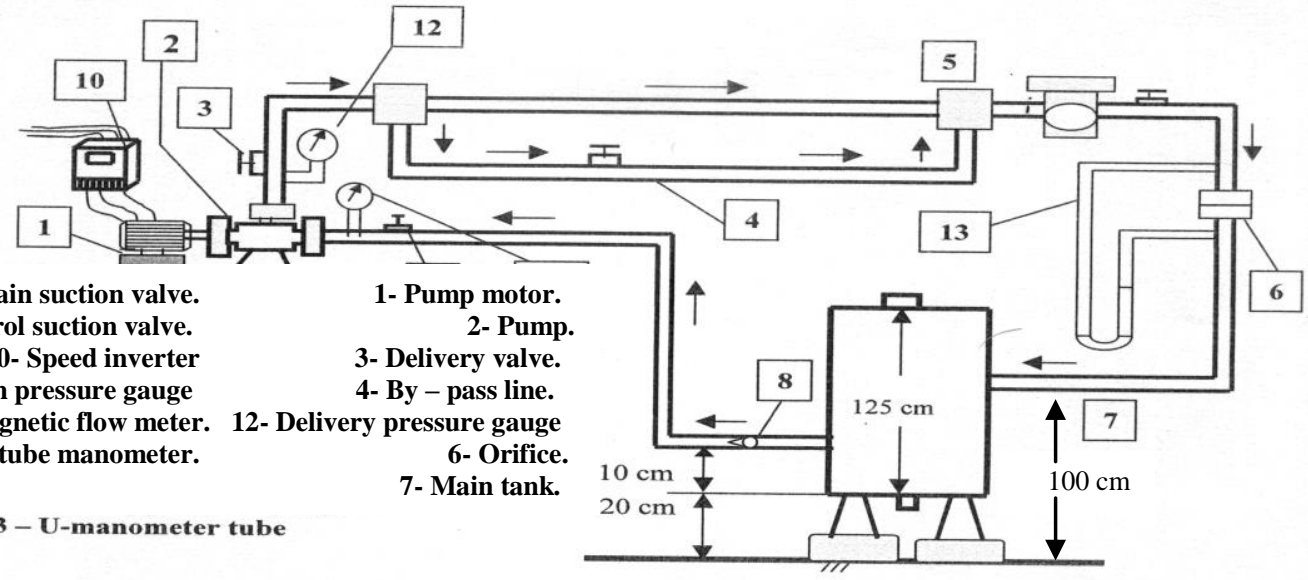

Fig. 1 Test circuit

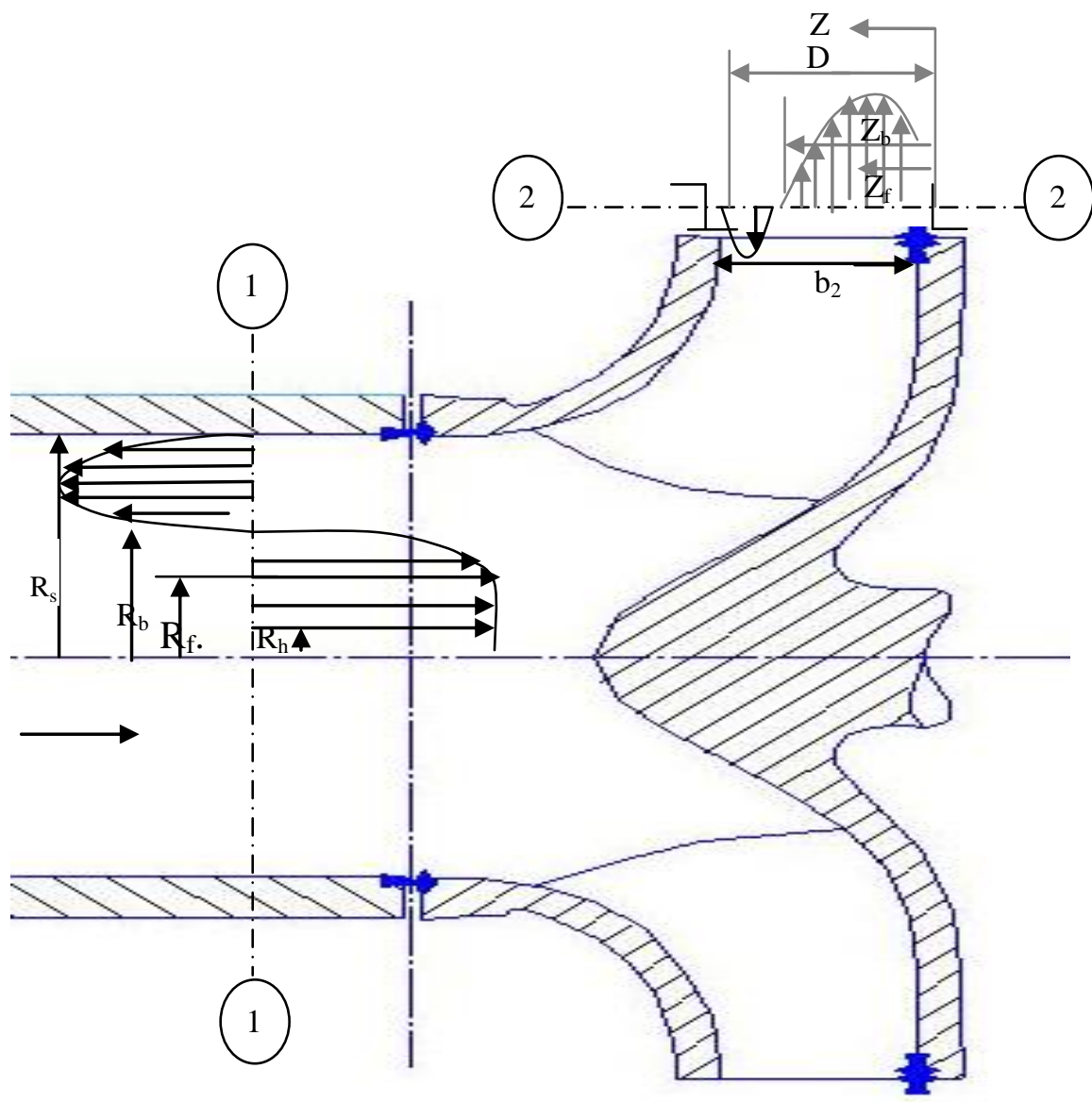

Fig. 2 Flow field with flow recirculation's at impeller inlet (1-1) and outlet (2-2) 
The volume flow rate through the system was measured by a calibrated electromagnetic flow meter, which was fitted on the delivery pipe. The diameter of the flow meter is $(5.08 \mathrm{~cm})$, and the output signal ranged from $(0.0-20 \mathrm{~mA})$ D.C. in linear proportion to the flow velocity which is ranged from $(0.0-11 \mathrm{~m} / \mathrm{s})$ at maximum discharge 22.3 lit / s, while the maximum flow rate from the pump is ( 8.6 lit / sec). The accuracy of the flow meter was $( \pm 1 \%)$ from the measured quantity of the flow rate. The pump used is a single stage centrifugal pump with spiral casing. The specific speed of the pump ( $\mathrm{Ns}=3.76)$. The pump is driven by an AC electrical motor of (7.5 hp), connected to the pump by a rigid coupling. The pump impeller outside and inside diameter were $(17.5 \mathrm{~cm})$ and $(5.4 \mathrm{~cm})$, respectively. The pump speed was controlled by a special speed inverter of type L100 with the following specifications: (* Model: L100055HFE*HP / kW: 7.5 / 5.5-* 50-60 Hz- * 3 ph 16.5 A) - Made in Japan. Pressure gauges, and control valves were connected in the system each as shown in the schematic diagram.

\subsection{Experimental Procedure}

After assembling the test circuit, the system was operated smoothly through the speed inverter without any major problems. Then the system was firstly evacuated from air, specially the gauges and manometers tube, to avoid the errors in the reading. Care has been taken when connecting the motor to the supply to avoid the reverse rotation of the motor. More accuracy should be taken when connecting the speed inverter with the motor to avoid the inverter damage. A circulating angular scale has been constructed with the delivery valve to maintain the percentage of the flow rate required and calibration processes were carried. The driving pump is operated through out the speed inverter to give smooth starting the motor. The pump performance test was taken at different rotational speed (from 2600 to $3000 \mathrm{rpm}$ ). The speed then was fixed at $2500 \mathrm{rpm}$ and quick measurements had been taken using the Pitot tube in order to find the speed at which the re-circulation flow starts.

The flattened Pitot tube designed according to reference [19]. The Pitot tube dimensions and its photograph are shown in Fig. (3-a), (3-b) and (3-c). For these flattened Pitot tube, the pressure coefficient remains near unity for a Reynolds number as low as 30. It has been fixed at the suction side of the pump at a distance of $(15 \mathrm{~mm})$ from the inlet flange on the pump entrance and $(8 \mathrm{~mm})$ downstream the impeller outlet. The Pitot tubes were fixed in such a way that they can be moved easily across the pipe. An $\mathrm{O}-$ ring seal has been fixed at the pipe wall to prevent any leakage of water or air. The Pitot tubes are moving on special scaled arm in order to adjust the measured point at the required radius. Due to circulation created by the small flow rates, the measured point of the Pitot tube has been taken at different directions in order to get the highest pressure difference on the manometer. Each reading has been taken after reaching the stability inside the manometer. The total and static pressure were measured across the pipe section with steps of $(2.5$ $\mathrm{mm})$. The measurements had been carried out at different percentages of flow rate ratio starting from $30 \%$ to $120 \%$ of the optimum flow rate.

The readings had been repeated for different rotational speeds, (from 2735 to $2980 \mathrm{rpm}$ ).

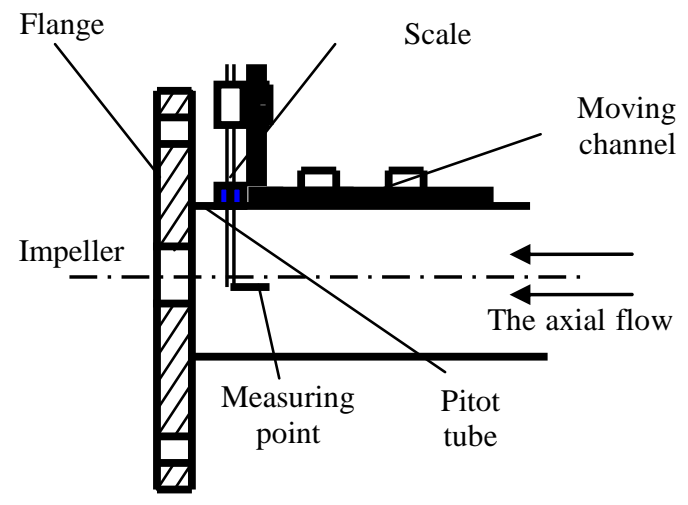

Fig.3-a

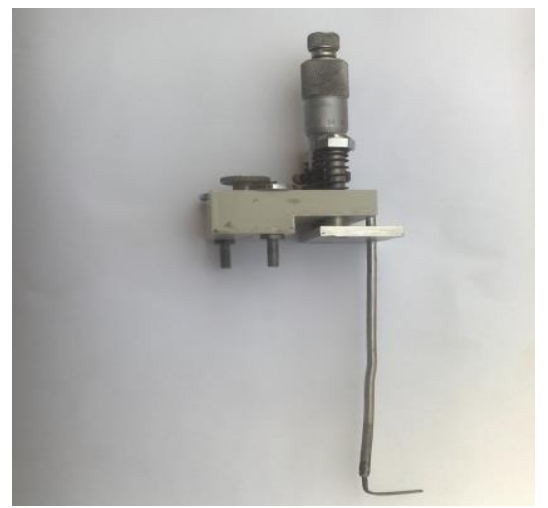

Fig.3-b

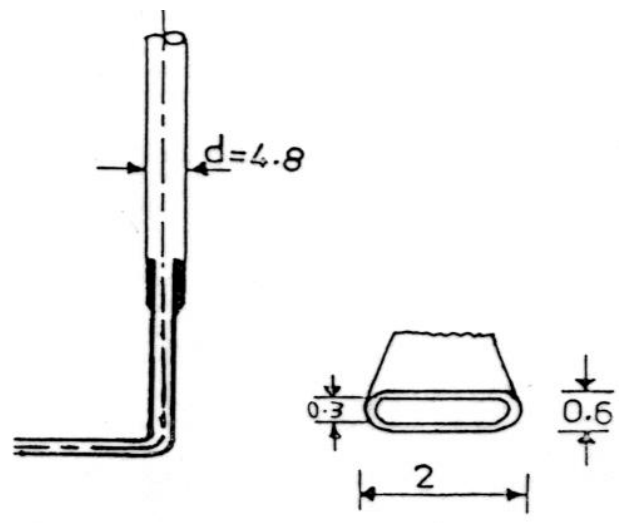

Flattened Pitot- tube Dims. in mm

Fig.3-c

Fig. 3 Mechanism of pitot tube measurement 


\section{RESULTS AND DISCUSSION}

\subsection{Flow Recirculation at Impeller Inlet}

The results of the axial flow velocity distribution along the radius of the suction pipe at the impeller inlet are shown in Fig. 4. This Figure is a sample of extensive measurements of the velocity distribution close to the inlet of the impeller at various operating conditions, Generally the results show that the velocity distribution along the pipe radius at high flow ratios of $\mathrm{Q} / \mathrm{Q}_{\text {shockless }} \geq 0.77$ is positive and no circulation flow appears and the fluctuating in the axial velocity is very small. At Q / $\mathrm{Q}_{\text {shockless }}=0.74$ the profiles are nearly uniform and the negative area is very small which is referred to small re-circulation created. For Q / Q shockless $<0.7$, the profiles show that the velocity distribution is not uniform and takes a wavy shape along the radius of the pipe. The distribution is characterized with creation of vortices in the core backward flow near the wall. This is referred to the creation of circulatory flow generated a region of low pressure in the central part of the vortex. The intensity of this vortex was increased when the pump was operating at lower flow rate and an increase in the pressure gradient will occur. Therefore, in the low pressure region a reverse flow was occurred due to the pressure gradient along the suction side of the pump. The back flow has a circumferential velocity of the impeller. The flow rate $\mathrm{Q}_{\mathrm{r}, \mathrm{s}}$ leaving the impeller reverses upstream of the impeller and enters the impeller again together with the effective through flow rate $Q$.

The annular cross section in front of the impeller can be divided in three zones: "recirculating back flow" between $R_{s}$ and $R_{b}$, "recirculating forward flow" between $R_{b}$ and $R_{f}$, and "through flow" between $R_{f}$ and $R_{h}$ (Fig. 2).

In test section 1-1 (Fig. 2) immediately upstream of the impeller $Q_{r, s}$ becomes higher and both $R_{b}$ and $R_{f}$ have lower values with decreasing flow rate $Q$ (where $\mathrm{Q}<\mathrm{Q}_{\text {crit,s}}$ ) as shown in Figure 5. Due to the displacement effect of the back flow, the mass averaged meridional velocity of the inflowing fluid becomes larger than that at equal flow rate (Q) without flow re-circulation. The ratio of meridional velocity with re-circulation to that without recirculation at impeller inlet is given by the expression,

$$
\frac{C_{m^{\prime}}}{C_{m}}=\frac{\mathrm{R}_{\mathrm{s}}^{2}-R_{h}^{2}}{\mathrm{R}_{\mathrm{b}}^{2}-R_{h}^{2}}\left(1+\frac{Q_{r}}{Q}\right)=\frac{C_{a^{\prime}}}{C_{a}}
$$

Where $C_{a}$ and $C_{a^{\prime}}$ are the axial velocities of pump inlet in the suction side without recirculation and with recirculation, respectively. $\mathrm{C}_{\mathrm{a}}$ and $\mathrm{C}_{\mathrm{a}}$ are obtained as follows:

$$
C_{a}=\frac{Q}{A}, \quad C_{a^{\prime}}=\frac{Q+Q_{r}}{A^{\prime}}
$$

where,

$$
A=\pi\left(R_{s}^{2}-R_{h}^{2}\right), \quad A^{\prime}=\pi\left(R_{b}^{2}-R_{h}^{2}\right)
$$

The re-circulated flow rate $\left(Q_{r}\right)$ is obtained from the following equation:

$$
Q_{r}=2 \pi \int_{R b}^{R S} \bar{V} \mathrm{rdr}
$$

\begin{tabular}{|c|c|c|c|}
\hline \multirow{2}{*}{\multicolumn{2}{|c|}{ Parameter }} & \multicolumn{2}{|c|}{ Uncertainty } \\
\hline & & Maximum & Minimum \\
\hline \multicolumn{2}{|c|}{ Local velocity $(\bar{V})$} & $0.847 \%$ & $0.667 \%$ \\
\hline \multicolumn{2}{|c|}{$\begin{array}{l}\text { Through flow rate } \\
\left(Q_{\text {th }}\right)\end{array}$} & $1.004 \%$ & $0.347 \%$ \\
\hline \multicolumn{2}{|c|}{$\begin{array}{l}\text { Recirculating flow rate } \\
\left(Q_{r}\right)\end{array}$} & $1.31 \%$ & $0.266 \%$ \\
\hline \multirow{2}{*}{$\begin{array}{l}\text { Axial flow } \\
\text { velocity }\end{array}$} & $C_{a}{ }^{\prime}$ & $2.12 \%$ & $1.65 \%$ \\
\hline & $\overline{C_{a}}$ & $4.9 \%$ & $1.7 \%$ \\
\hline \multirow{2}{*}{$\begin{array}{l}\text { Meridional } \\
\text { velocity }\end{array}$} & $\overline{C_{m}{ }^{\prime}}$ & $1.9 \%$ & $0.58 \%$ \\
\hline & $C_{m}$ & $1.27 \%$ & $0.44 \%$ \\
\hline
\end{tabular}

Where, $\bar{V}$ is the average velocity at a radius $\mathrm{r}$. The uncertainty of results is summarized in Table 1

Table 1, Summary of the Uncertainty

At zero flow rate, $\mathrm{Q}_{\mathrm{r}, \mathrm{s}} / \mathrm{Q}_{\mathrm{opt}} \approx 0.6$. The circumferential component at which $\mathrm{Q}_{\mathrm{r}, \mathrm{s}}$ leaves the impeller increases with decreasing $\mathrm{Q}$ and is almost as large as $\mathrm{u}_{1}$ at $\mathrm{Q}=0.0$.

The transfer of moment of momentum and energy to the recirculating flow which takes place inside the impeller increases with decreasing the flow rate $\mathrm{Q}$ as shown in Figure 6. 
M. A. Hosien and S. M. Selim, "Operation of Centrifugal Pump at Part Load Conditions"

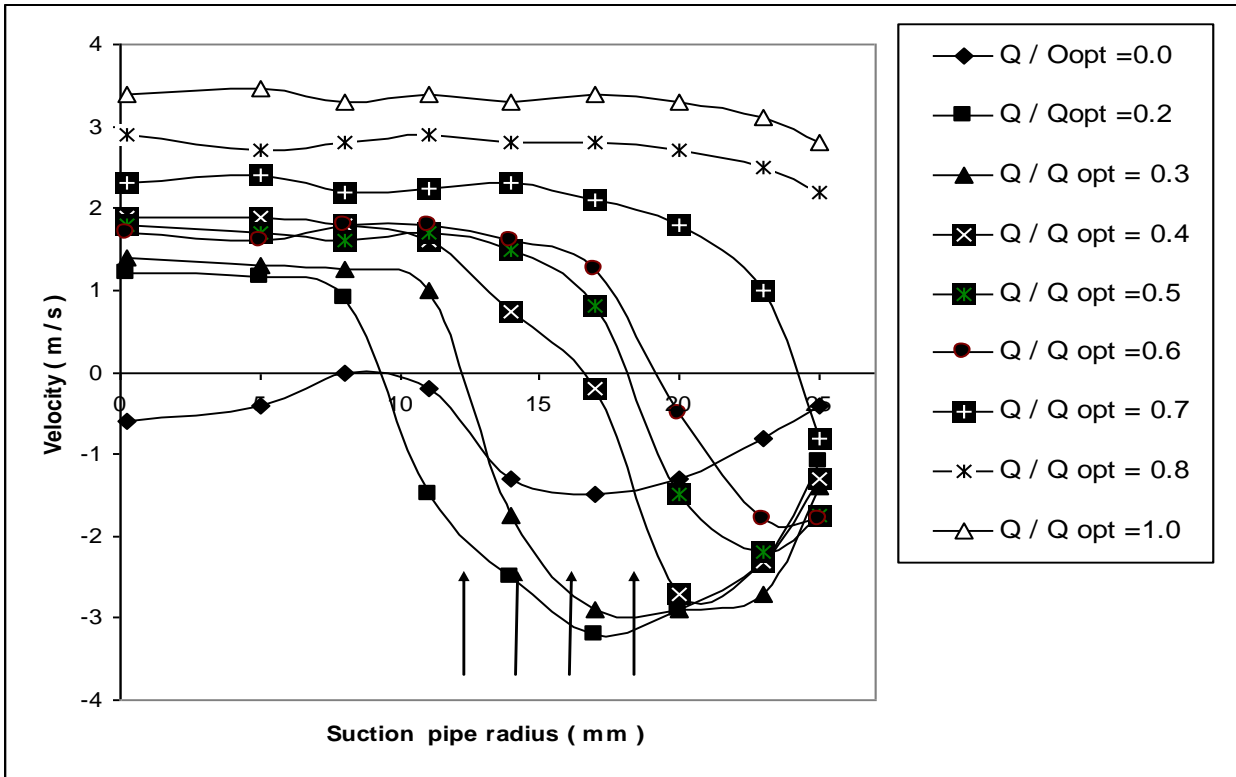

Fig. 4 Velocity distributions at section (1) near the inlet of the impeller at various ratios of flow rate to optimum flow rate

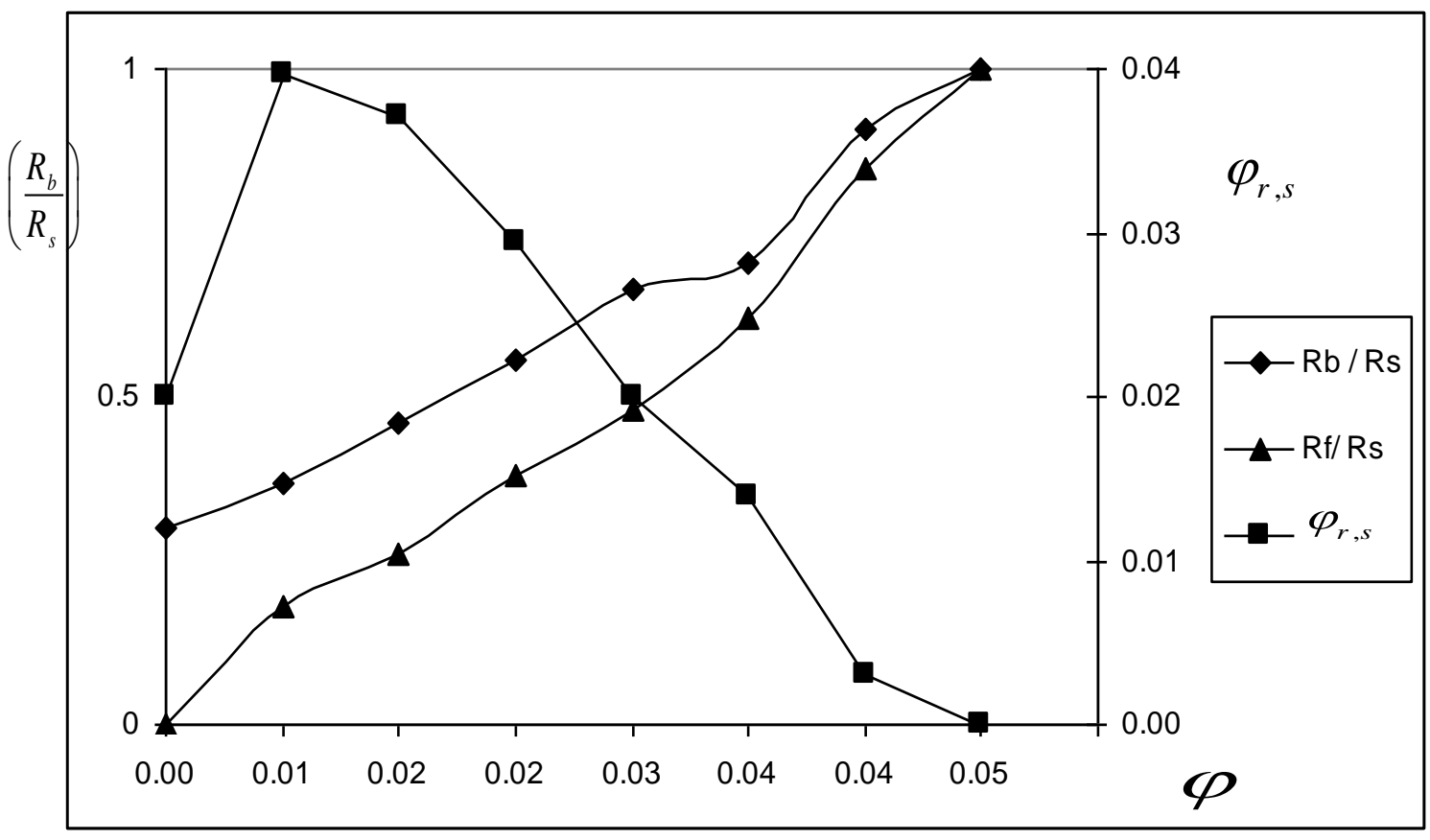

Fig. 5 Flow rate coefficient and radii of recirculating flow at impeller inlet 


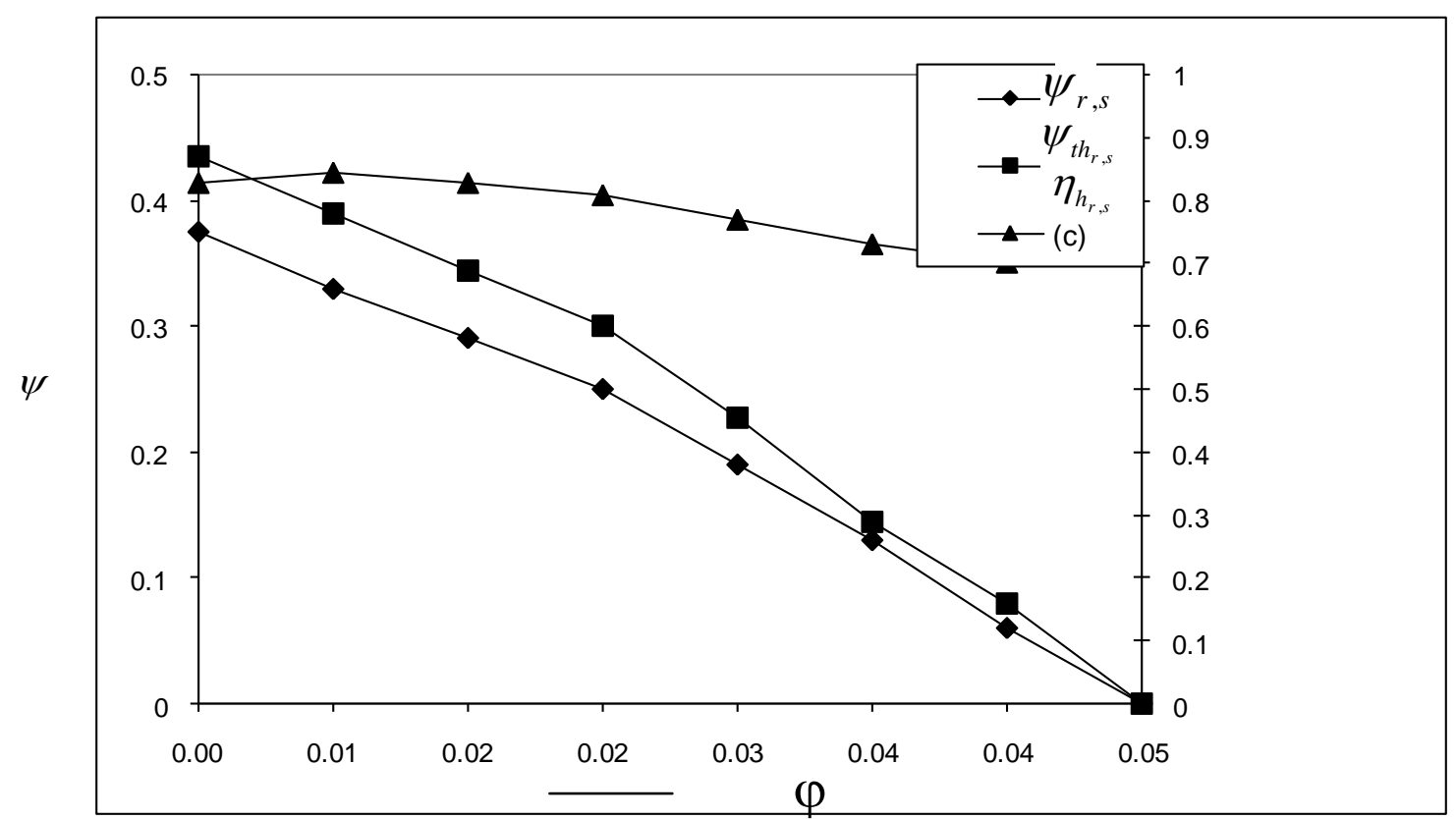

Fig. 6 Transfer of momentum and energy to recirculating flow at impeller inlet.

This gives rise to an increasing length of the flow recirculation $\mathrm{L}_{\mathrm{r}, \mathrm{s}}$ in the suction pipe of the tested pump. At $\mathrm{Q}=0.0$ it is found that $\mathrm{L}_{\mathrm{r}, \mathrm{s}} \approx 8$. Ds . Within $\mathrm{L}_{\mathrm{r}, \mathrm{s}}$, part of the moment of momentum of the recirculating flow is showed down by wall friction, part of it is transferred to the through flow. The forward flow $\left(\mathrm{Q}+\mathrm{Q}_{\mathrm{r}, \mathrm{s}}\right)$, therefore, enters the impeller with a corotating swirl. Together with the increased meridional velocity the co rotating swirl reduces the incidence angle at the impeller inlet (Fig. 7). This has a positive effect on the shock loss at the impeller inlet.

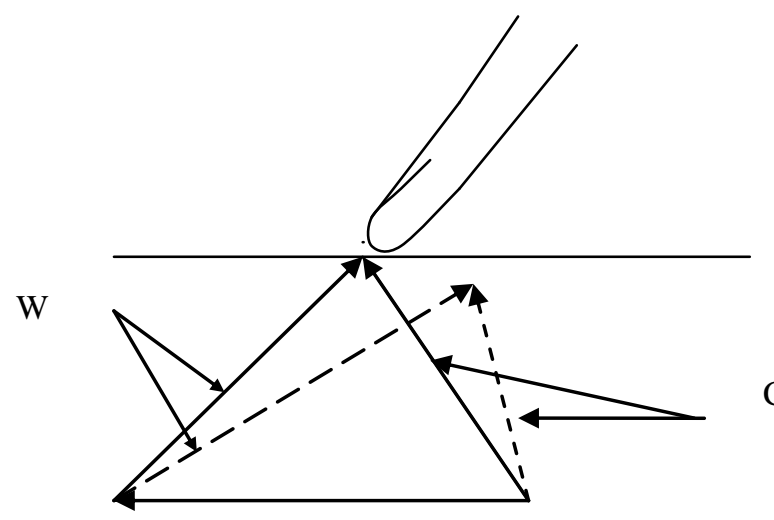

$\mathrm{U}$

Fig. 7 Velocity triangles at impeller inlet - with flow recirculation, without flow recirculation
Test performed at $\mathrm{Q}=0.0$ with an impeller either open or closed at the outlet in both cases resulted in the same flow field upstream of the impeller inlet. Therefore, it is concluded that, at least in the case of the impeller used in the present investigation, the recirculation flow at the impeller inlet is not influenced by the flow processes at the impeller outlet. The distributions of velocity along the pipe radius at zero flow rates, Fig. 4, indicated that there was a rotating vortex core at the centre of the suction pipe at impeller inlet. This indicated that there was a rotating vortex core with flow reversal in the middle of the suction pipe.

\subsection{Flow Recirculation at Impeller Outlet}

Figure 8 shows that, measurements of the velocity distribution along the radius of the delivery pipe just a little downstream of the impeller outlet. When the flow is throttled a local back flow initially develops downstream of the impeller. This back flow, which in the case of the test impeller takes place on the shroud side. This is probably caused by too much flow deceleration inside the stationary diffuser in connection with non-uniform outflow out of the impeller. The area of back flow increases upstream while $Q$ decreases, and reaches the impeller outlet at $\mathrm{Q}=\mathrm{Q}_{\text {crit,d }}$.

For the test impeller $\mathrm{Q}_{\text {crit,d }}$ is larger than $\mathrm{Q}_{\text {crit, } \mathrm{s}}$. The circumferential velocity component of the back flow depends on the design of diffuser but, in any cases, causes a heavy shock when entering the impeller. Recirculating flow rate $Q_{r, d}$ is redirected inside the impeller, where it is given moment of momentum 
and energy by the impeller blading, and then leaves the impeller again together with through- flow rate $\mathrm{Q}$.

As in test section 1-1, it is also possible to divide the flow in "recirculating back flow", "recirculating forward flow" and "through flow" in test section 2-2 downstream of the impeller. The limits are at $\mathrm{Z}=\mathrm{Z}_{\mathrm{b}}$ and $\mathrm{Z}=\mathrm{Z}_{\mathrm{f}}$ (Fig. 2). Figure 9 shows the variation of $\mathrm{Q}_{\mathrm{r}, \mathrm{d}}, \mathrm{Z}_{\mathrm{b}}$ and $\mathrm{Z}_{\mathrm{f}}$ with flow rate, $\mathrm{Q}$. At $\mathrm{Q}=0.0, \mathrm{Q}_{\mathrm{r}, \mathrm{d}}$ is approximately twice $\mathrm{Q}_{\mathrm{r}, \mathrm{s}}$. Fig. 9 indicates that both $\mathrm{Z}_{\mathrm{b}}$ and $\mathrm{Z}_{\mathrm{f}}$ are increasing with increasing the flow rate. In addition, at $Q=0.0, Z_{f}$ is equal to zero while $\mathrm{Z}_{\mathrm{b}}$ has a certain value. As the effective width decreases with decreasing $\mathrm{Q}$, the mass averaged meridional velocities $\bar{C}_{m_{2}}$ are larger, because the mean circumferential components smaller, and consequently the outlet flow angle from the impeller lager than they would be at equal flow rate without flow recirculation. This has a positive effect on the losses of the through flow in the diffuser (smaller wall friction losses in a vaneless, smaller shock losses in a vaned diffuser).

With decreasing $\mathrm{Q}$, the transfer of moment of momentum and energy to the re-circulating flow also increases as shown in Fig. 10. At the impeller outlet, circumferential component $\left(\mathrm{Cu}_{2}\right)$ and the total pressure $\left(\mathrm{P}_{\text {tot }}\right)$ are large in the through flow zone. It, therefore, is unlikely for the moment of momentum or energy to be transferred from the recirculating flow to the through flow in the vanless diffuser.

Test carried out with an impeller closed at the inlet showed that the flow recirculation at the impeller outlet was not influenced by the flow processes at the impeller inlet.

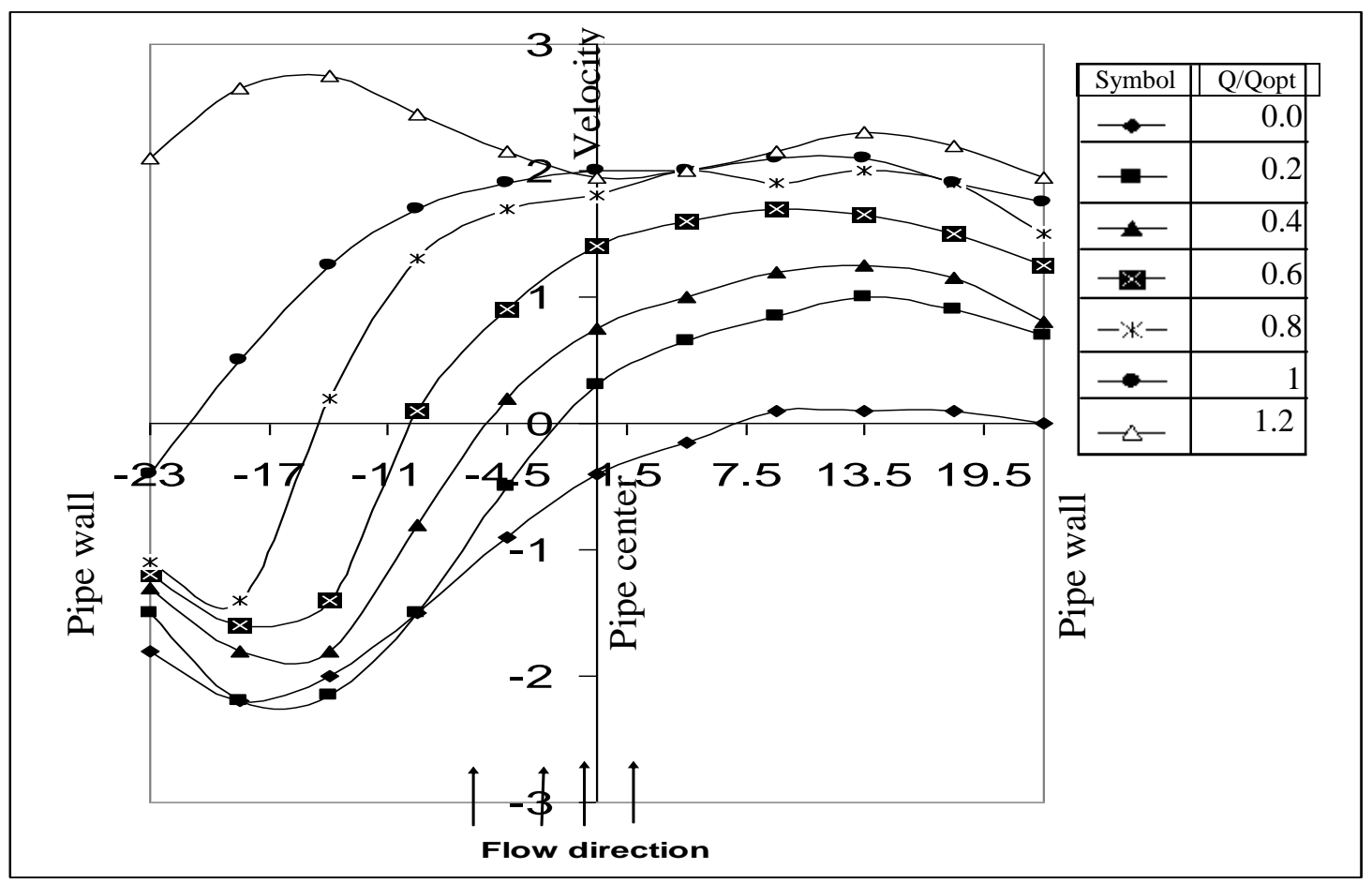

Fig. 8 Velocity distributions near the outlet of the impeller at various flow rates. 
M. A. Hosien and S. M. Selim, "Operation of Centrifugal Pump at Part Load Conditions"

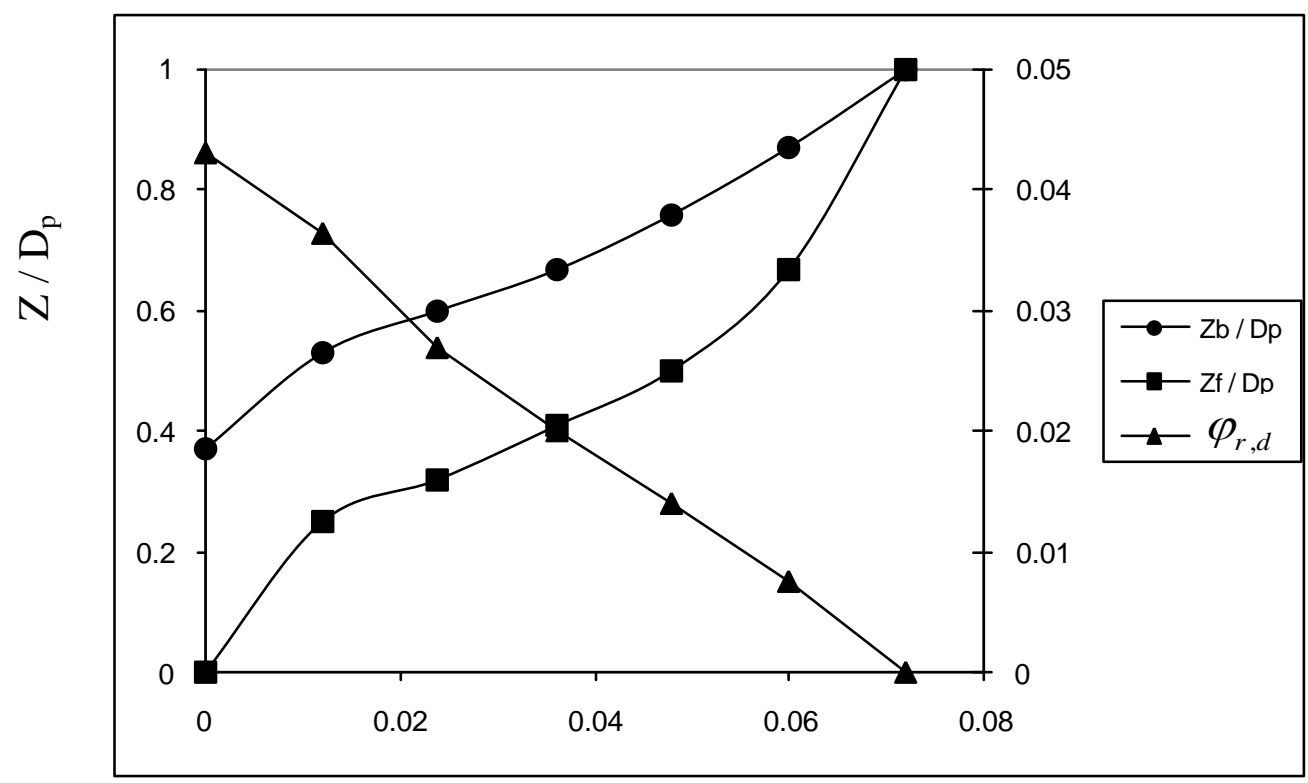

$\varphi$

Fig. 9 Flow rate coefficients and radii of recirculating flow at impeller outlet

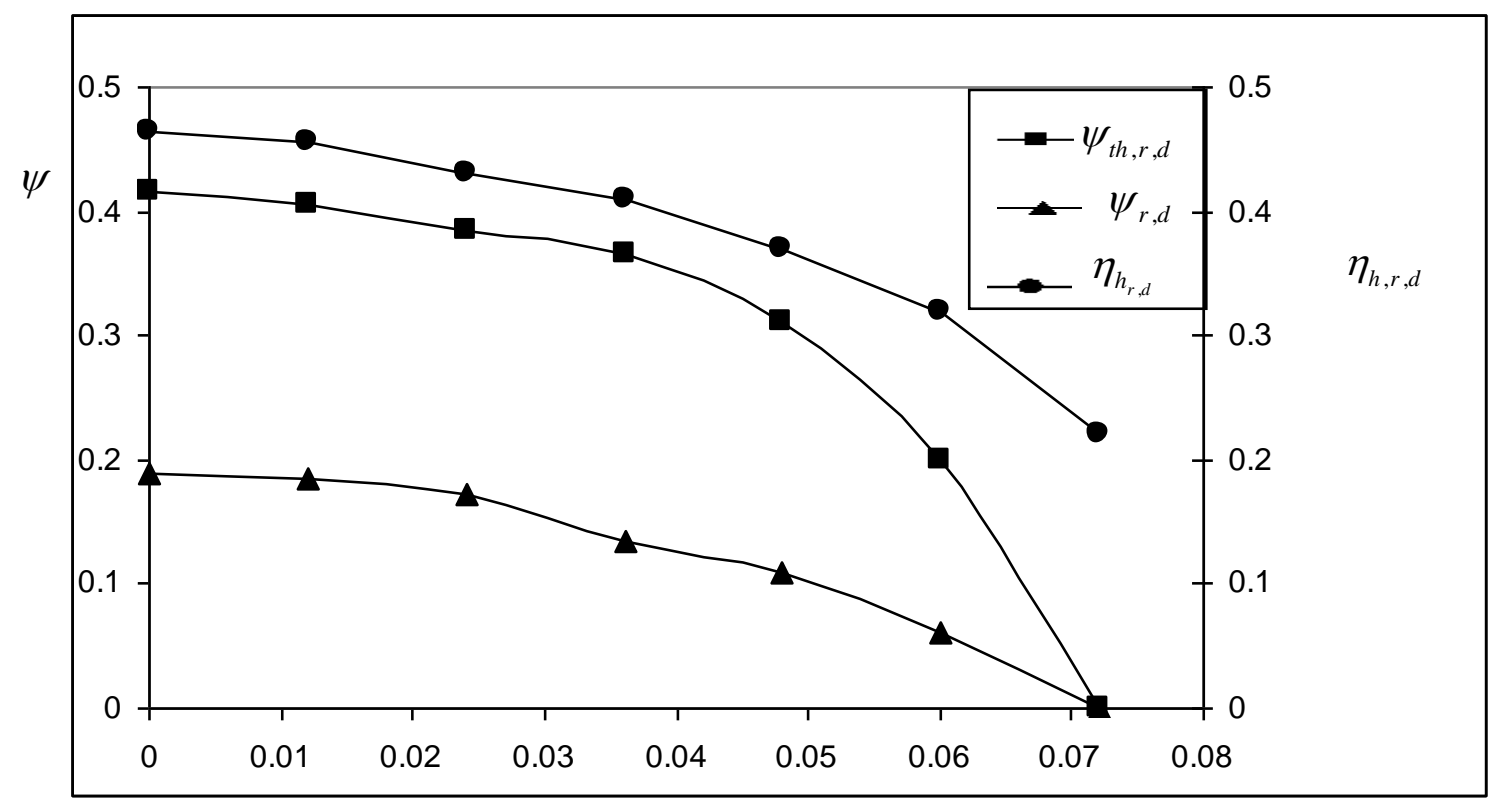

$\varphi$

Fig. 10 Transfer of momentum and energy to recirculating flow at impeller outlet 


\section{LOSS ANALYSIS}

The heads calculated from the increase of moments of momentum and energy of through flow $\mathrm{Q}$ is shown in Figure 11. When there are flow circulations, $\mathrm{H}_{\mathrm{th}, \mathrm{f}}-\mathrm{Q}$ curve deviates from the linear course to smaller values. This effect is partly due to the co rotating swirl at impeller inlet and partly to the decrease of the mean circumferential components at outlet $\left(\bar{C}_{u 2}\right)$ as a result of the smaller effective outlet width. Hydraulic impeller efficiency $\eta_{\mathrm{h}, \mathrm{imp}}$ reaches its maximum value of 0.98 at nearly shock less inlet condition. In addition, at part load operation with flow recirculation's, hydraulic efficiency $\eta_{\mathrm{h}, \mathrm{t}}$ calculated from the increase of moments of momentum and energy of he through flow remains well above 0.9 .

At $\mathrm{Q}<\mathrm{Q}_{\text {crit }}$ the power input to the blading also includes the portions necessary to maintain the flow recirculation's.

$$
p_{t h}=\rho g\left(Q H_{t h, t}+Q_{r, s} H_{t h_{r, s}}+Q_{r, d} H_{t h_{r, d}}\right)
$$

Between $\mathrm{Q}=\mathrm{Q}_{\text {crit }}$ and $\mathrm{Q}=0.0$, the magnitude of $\mathrm{P}_{\text {th }}$ (and hence $\mathrm{P}$ as well) is increasingly determined by the flow recirculation's. When $\mathrm{Q}=0.0, \mathrm{P}_{\mathrm{thr}, \mathrm{d}}$ is about twice as large as $\mathrm{P}_{1, \mathrm{df}}$.

Inside the impeller losses occur when energy is transferred to the through flow and to recirculating flows. These losses can be quantified using the partial efficiencies $\eta_{\mathrm{h}, \mathrm{t}}$ (Fig. 11) for the energy transfer to the through flow and $\eta_{\mathrm{h}, \mathrm{rs}}$ respectively $\eta_{\mathrm{h}, \mathrm{rd}}$
(Fig.6 and Fig. 10 ) for the energy transfer to the recirculating flows.

Taking $\mathrm{P}_{\text {th }}$ from equation (1) and the total energy increase of the main flow and that of the recirculating flows,

$$
\left(E_{\text {out }}-E_{\text {in }}\right)=\rho \cdot g\left(Q H_{t}+Q_{r, s} H_{r, s}+Q_{r, d} H_{r, d}\right)
$$

The hydraulic efficiency and the hydraulic losses of the impeller may obtained, if it is regarded on its own (curves a in Figure 12). Whether the energy transferred by the impeller to the re-circulating flows can, to some extent, be used, or whether all of it is to be considered as loss for the pump, depends on the flow processes outside the impeller.

If for instance, the energy transferred to the recirculating flow at the impeller inlet is judged to be useable energy, then curves b in Figure 12 apply. But for this to be so, the energy should ideally be transferred completely from the recirculating flow to be the through flow outside the impeller. In this case the energy transferred to the re-circulating flows can also be regarded as additional impeller losses. One obtains the lower limit of the hydraulic efficiency and the upper limit of the hydraulic impeller losses (curves $\mathrm{c}$ in Figure 12).

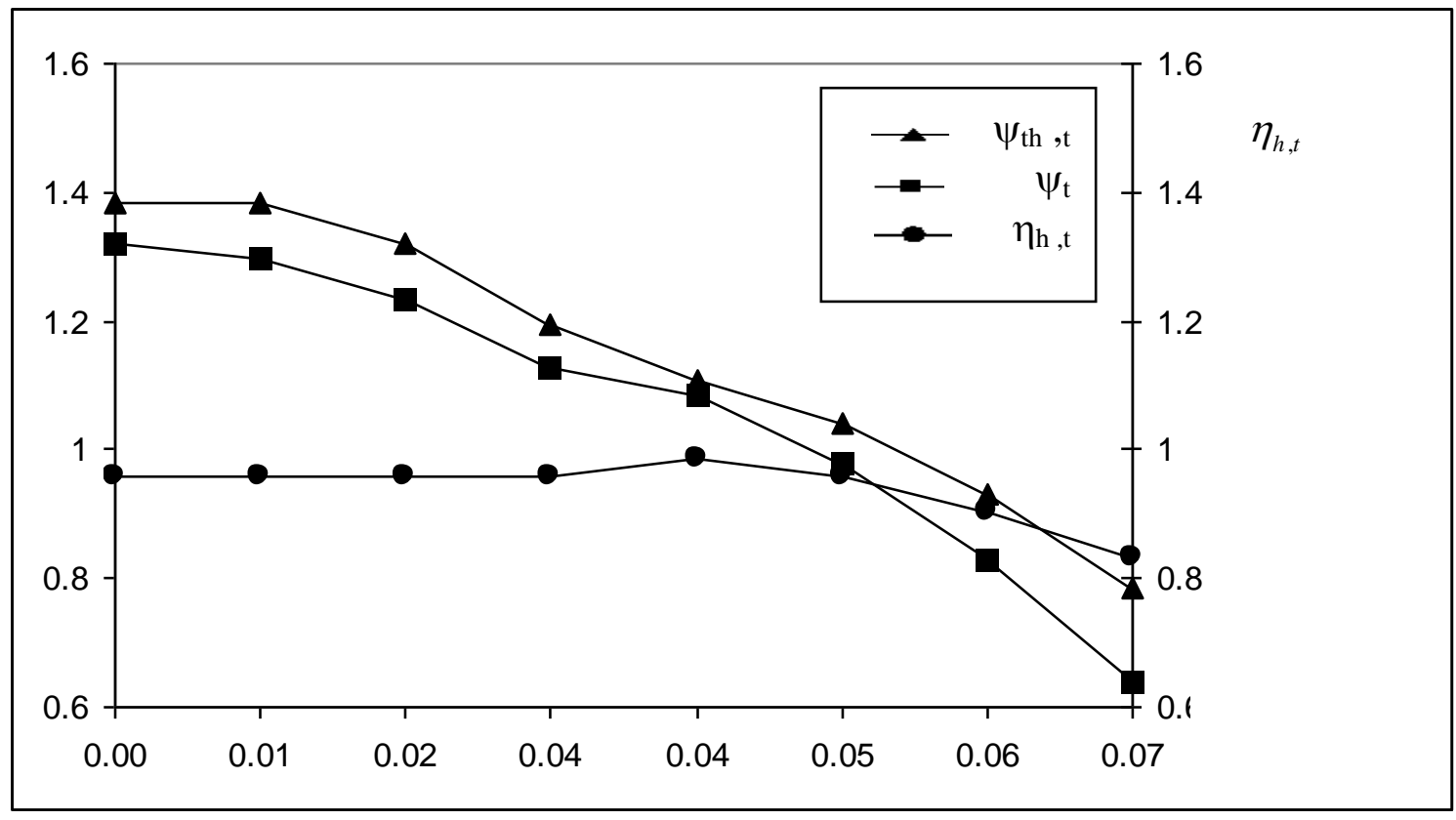

Fig. 11 Transfer of momentum and energy to through flow 


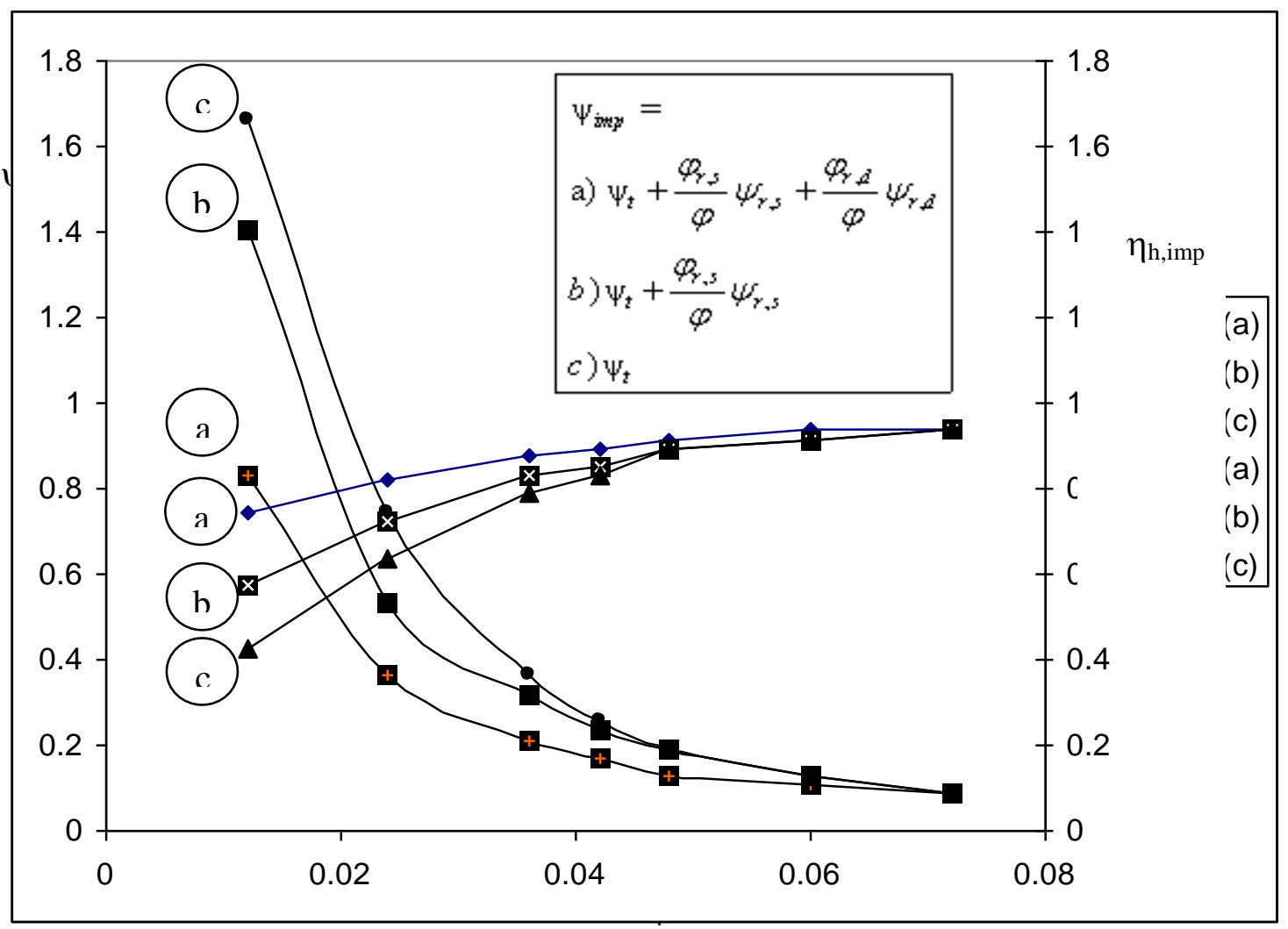

Fig. 12 Impeller head losses and impeller hydraulic efficiency at part load operation

\section{CONCLUSIONS}

The main conclusions of this extensive experimental study could be summarized as flows:

1. At reduced flow rates recirculating flow at impeller inlet and outlet was noticed.

2. The recirculating flow velocity distribution at impeller inlet and outlet was characterized with creation of recirculating back flow, recirculating forward flow and through main flow.

3. The recirculating back flow at impeller inlet was appeared at low flow rates Q / $\mathrm{Q}_{\text {opt }} \leq 0.7$. While the re-circulating backflow at impeller outlet was appeared at flow rates $\mathrm{Q} / \mathrm{Q}_{\mathrm{opt}}>1$.

4. At zero flow rates, the flow rate of recirculating flow at impeller outlet was found to be twice that at impeller inlet.

5. The recirculating back flow region increased as the flow rate decreased.

6. The transfer of moment of momentum and energy to the recirculating flow increased with decreasing the flow rate.
7. The energy transferred to the recirculating flows can be regarded as additional impeller losses. Therefore, the lower limit of the hydraulic efficiency could be obtained.

8. The effect of recirculating flow on the pump performance must be considered in the development of the theoretical prediction of the performance of pumps which operate over a wide range of capacities including extremely low flow rates.

\section{NOMENCLATURE}

$A^{\prime}$ and A: cross sectional area of the flow with and without recirculation.

b: blade height.

$\mathrm{C}_{\mathrm{m}}$ : flow velocity without recirculation.

$\mathrm{C}_{\mathrm{m}}{ }^{\prime}$ : flow velocity with recirculation.

D: impeller diameter.

$\mathrm{D}_{\mathrm{p}}$ : pipe diameter.

E: energy.

g: acceleration. 
P: power

Q: through flow rate.

$\mathrm{Q}_{\mathrm{r}}$ : recirculating flow rate.

$\left(\mathrm{Q}+\mathrm{Q}_{\mathrm{r}}\right)$ : Forward flow rate.

$\mathrm{Q}_{\mathrm{r}, \mathrm{b}}$ : recircularing back flow rate.

$\mathrm{Q}_{\mathrm{r}, \mathrm{s}}$ : recirculating forward flow rate.

$\mathrm{Q}_{\mathrm{r}, \mathrm{s}}$ : recirculatingflow rate at suction side.

$\mathrm{Q}_{\text {crit,s: }}$ : the flow rate where the recirculation starts.

$\mathrm{Q}_{\text {opt}}$ : optimum flow rate.

$\mathrm{U}_{1}$ : peripheral velocity.

$\mathrm{W}_{1}$ : inlet relative velocity.

$\mathrm{W}^{\prime} 1$ : inlet relative circulating velocity.

$\mathrm{R}_{\mathrm{b}}$ and $\mathrm{Z}_{\mathrm{b}}$ : the radius where the back flow starts at suction and delivery sides.

$\mathrm{R}_{\mathrm{f}}$ and $\mathrm{Z}_{\mathrm{f}}$ : the mean radius of forward flow at the suction and delivery sides.

$\mathrm{R}_{\mathrm{s}}$ : the suction pipe radius.

$\mathrm{R}_{\mathrm{h}}$ : the hub radius.

$\rho$ : density.

$\Psi$ : impeller head coefficient.

$\Phi$ : flow coefficient.

$\eta_{\mathrm{h}}$ : hydraulic efficiency.

\section{Subscripts}

th: theoretical.

s: suction.

d: delivery.

r: recirculating

t and tot: total.

Imp: impeller.

2: at outlet of the impeller.

in: inlet.

out: outlet.

\section{REFERENCES}

[1] Fraser, W. H., "Recirculation in Centrifugal Pumps", Winter Annual Meeting of ASME, Nov. 16, 1981.

[2] Fraser, W. H., "Flow Recirculation in Centrifugal Pumps", Texas A. and Turbomachenary Symosium. Hoaston, Texas, Dec. 1981.

[3] Cooper, P., "Panel Session on Specifying Minimum Flow", Proceedings of the Texas A and M Intr. Pump User Symposium, Housten, Texas, PP. 177-192, 1988.

[4] Vlaming D., J., "Optimum Inlet Geometry Minimum NPSH Requirements for Centrifugal Pumps", ASME Journal of Fluids Engineering, Vol. 81, PP. 25-28, 1989.
[5] Peck, J. F. ,"Investigation Concerning Flow Conditions in a Centrifugal Pump, and the Effect of Blade Loading on Head Slip", Proc. J. Mech.E., Vol.62, P. 406, 1950.

[6] Schiavello, B. and M.Sen., "On the Prediction of the Reverse Flow Onset at the Centrifugal Pumps Inlet", ASME Conf. Performance Prediction of Centrifugal Pumps and Compressors. New Orleans, P. 261, 1980.

[7] Guelich, J. F., Bolleter, U. and Simon, A., "Feed Pump Operation and Design Guidelines", Sulzer Brothers Ltd., Winterthur, Switzerland, Also McCloskey, EPRI Publication TR102102, T. Electric Power Research Institute, Palo Alto, California, June, 1993.

[8] Sen. M., "Inlet Flow in Centrifugal Pumps at Partial Delivery", Government Publication, Vol. 81- 0437, Von Karman Institute, Rhode Saint Genese, Belgium, June, 1979.

[9] Kaupert, K.A., et al.,"A First Analysis of Flow Field Hysterisis in a PumpImpeller", ASME Journal of Fluids Engineering, PP. 685-691, December, 1996.

[10] Schweiger F. and kercan V., "Flow and Cavitation in Centrifugal Pumps at Partial Loads", Strojniski Vestnik Mechanical Journal, Vol. 25, No. 11-12, 1979.

[11] Salemi, C., and DiMatteo, V., "Slip Factor Calculation in Centrifugal Pumps by Means of Evaluation of Wall Boundary Layer " ,ASME Performance Prediction of Centrifugal Pumps and Compressors, 22 ${ }^{\text {nd }}$ Annual Fluid Engineering Conference, New Orleans, Louisiana, March 9-13, 1980.

[12] Dupont Ph., "Numerical prediction of cavitation in pumps", Swiss Federal Institute of Technology of Lausanne, Switzerland, PP. 5965,2000 .

[13] Hofmann M., Stoffel B. Friedrichs J., and Kosyna G., "Similarities and Geometrical Effects on Rotating Cavitation in Two Scaled Centrifugal Pumps", CA V 2001: Fourth International Symposium on Cavitation, California Institute of Technology, Pasadena, USA, PP.1-8, June 20-23, 2001.

[14] Wuibaut,G., Dupont, P., Bois, G. and Caignaert, G. "PIV Measurements in the Impeller and the Vaned Diffuser of a Radial Flow Pump in Design and Off-design Operating Conditions",11th IAHR International Meeting of the Work Group on the Behavior of Hydraulic Machinery Under Steady Oscillatory Conditions Stuttgart, Germany, October 8-10, 2003 19/11/03 
[15] Europump, European Association of Pump Manufacturers, "Operating Rotodynamic Pumps away from Design Conditions", The European Guides to Advanced Pumping Technology, Vol 3, 2000.

[16] Bois, G.,"Introduction to Design and Analysis of High Speed Pumps", In Design and Analysis of High Speed Pumps (pp. 1-1 - 1-20), 2006. Educational Notes RTO-EN-AVT-143, Paper 1. Neuilly-sur-Seine, France: RTO.

[17] Rey, R., Guiton, P., Kermarec, Y. and Vullioud, G., "Etude statistique sur les aracteristiques à debit partiel des pompes centrifuges et sur la determination approximative du débit critique", La houille Blanche 1982; 2/3; 107-120.

[18] Feng, J., Benra, F.-K. and Dohmen, H.J.,"Unsteady Flow Visualization at Part-Load Conditions of a Radial Diffuser Pump: by PIV and CFD", The Visualization Society of Japan, Journal of Visualization, Vol. 12, No. 1, (2009), 65-72.

[19] Macmillan, F. A. "Viscous Effects on flattened Pitot Tubes at Low Speeds", J. Roy. Aeronaut. Soc., Technical Note, 1954.

\section{APPENDIX}

Formula, used to evaluate various parameters:

$$
\begin{gathered}
\varphi=\frac{Q}{\pi D_{2} b_{2} U_{2}} \\
\varphi_{r, s}=\frac{Q_{r}}{\pi D_{2} b_{2} U_{2}}
\end{gathered}
$$

The following are obtained from the axial velocity distribution - radius curves:

$$
R_{b}, R_{f} \text { and } \overline{V_{r}}=\frac{\sum V_{r}}{n}
$$

The calculated parameters are:

$$
\begin{aligned}
& C_{m}=\frac{Q}{\pi\left(R_{s}^{2}-R_{h}^{2}\right)} \\
& Q_{r}=\pi\left(R_{b}^{2}-R_{s}^{2}\right)\left(\frac{\sum V_{r}}{n}\right)=2 \pi \int_{R_{s}}^{R_{b}} \bar{V} r d r
\end{aligned}
$$

$$
\begin{aligned}
& C_{m}^{\prime}=\frac{\left(Q+Q_{r}\right)}{\pi\left(R_{b}^{2}-R_{h}^{2}\right)} \\
& Q=\pi\left(R_{b}^{2}-R_{h}^{2}\right) \bar{V} \\
& M_{I}=\rho \int r c_{n} c_{u} d A \\
& \stackrel{0}{E}=\int c_{n} P_{t o t} d A \\
& H_{t h, r, d}=\frac{\omega\left(M_{I, \text { out }}-M_{I, \text { in }}\right)_{r, d}}{\rho g Q_{r, d}} \\
& H_{r, d}=\frac{\left(\stackrel{o}{E_{\text {out }}-\stackrel{o}{\text { in }}}\right)_{r, d}}{\rho g Q_{r, d}} \\
& \eta_{h, r, d}=\frac{H_{r, d}}{H_{t h, r, d}} \\
& \psi=\frac{2 g H}{U_{2}^{2}} \\
& H_{t h, t}=\frac{\omega\left(M_{I_{2}}-M_{I_{1}}\right)_{t}}{\rho g Q} \\
& H_{t}=\frac{\left(\begin{array}{c}
0 \\
E_{2}-E_{1}
\end{array}\right)_{t}}{\rho g Q} \\
& \eta_{h, t}=\frac{H_{t}}{H_{t h, t}}
\end{aligned}
$$

$\psi_{t}=\psi_{t h, t o t}-\psi_{i m p}$$$
\psi_{t h, t o t}=\psi_{t h, t}+\frac{\varphi_{r, s}}{\varphi} \psi_{t h, r, s}+\frac{\varphi_{r, d}}{\varphi} \psi_{t h, r, d}
$$ 